\section{Single-strand conformation polymorphism (SSCP) at the D8S86 locus}

M.lizuka, K.Hayashi and T.Sekiya

Oncogene Division, National Cancer Center Research

Institute, 1-1, Tsukiji 5-Chome, Chuo-ku, Tokyo 104, Japan

Source/Description: pNCO907 contains a 500-bp PstI fragment of pNC0901 inserted into pUC19 as described previously (1). The sequences for PCR primers were determined. A fragment of about $500-\mathrm{bp}$ is amplified.

PCR Primers:

8.86-1 = TATCAGATAGAATGTGTGGG

8.86-2 = CTCTGAGGCCATGGAACAGA

Polymorphism: Two types of alleles (D1 and D2) were found by SSCP analysis.

Frequencies:

$\mathrm{D} 1=0.64$,

$\mathrm{D} 2=0.36$

Determined in 14 unrelated individuals. The observed heterozygosity is 0.50 .

Chromosomal Localization: Chromosome 8, assigned with a panel of human-mouse somatic cell hybrids (1).

Mendelian Inheritance: Codominant segregation, observed in one informative family (Figure).

$P C R$ and SSCP Conditions: 5 '-end-labelled primers $(0.5 \mathrm{pmol}$ each) were added to a $5 \mu \mathrm{l}$ mixture of $50 \mathrm{ng}$ genomic DNA, $1 \times$ PCR buffer specified by Cetus Corporation, $125 \mu \mathrm{M}$ concentrations of deoxynucleotide triphosphates (dATP, dCTP, dTTP and dGTP), and 0.125U Taq DNA polymerase. Thermal conditions were 32 cycles at $94^{\circ} \mathrm{C}$ for $20 \mathrm{sec}$ and at $65^{\circ} \mathrm{C}$ for $2 \mathrm{~min}$ (2). Denatured PCR products were separated at $30 \mathrm{~W}$ at room temperature in $5 \%$ polyacrylamide gel containing $5 \%$ glycerol with vigorous cooling.

Other Comments: The probe pNCO907 also detects three RFLPs (EcoRI, SphI and TaqI) (3).

Acknowledgements: This work was supported in part by a Grantin-Aid from the Ministry of Health and Welfare for a Comprehensive 10-Year Strategy for Cancer Control, Japan, a Grant-in-Aid for Cancer Research from the Ministry of Education, Science and Culture, and a grant from the Special Condition Fund of the Science and Technology Agency of Japan.

References: 1) lizuka,M. et al. (1990) Cancer Res. 50, 3345-3350. 2) Mashiyama,S. et al. (1990) Technique 2, 304-306. 3) Iizuka,M. et al. (1991) Nucl. Acids Res. 19, 680.

\section{Hindlll-polymorphism in the LPL- gene detected by PCR}

T.Bruin, P.W.A.Reymer, B.E.Groenemeyer, P.J.Talmud and J.J.P.Kastelein

Division of Hemostasis, Thrombosis and Atherosclerosis, Academic Medical Center, Meibergdreef 9, 1105 AZ, Amsterdam, The Netherlands and ${ }^{1}$ Charing Cross Sunley Research Centre, 1 Lurgan Avenue, Hammersmith, London, W6 8LW, UK

Source/Description: We designed two oligonucleotides derived from the sequences in exon 8 and 9 in the LPL-gene (1) to amplify the sequence around a polymorphic HindIII-site. This polymorphism is located in intron 8 (2), in contrast to the HindIIIpolymorphism in the $3^{\prime}$ untranslated region as described by Oka et al. (3). The amplified fragment has a size of $1200 \mathrm{bp}$. The polymorphism in intron 8 was detected upon digestion of the PCR-product with HindIII.

Primer Sequences:

Hind5: 5'-AGTGATTCATACTTTAGCTG-3'

Hind3: 5'-TGAGACACTTTCTCCCTAGA-3'

Frequency:

Allele H1 (1200 bp) 0.33

Heinzmann et al. (5) Funke et al. (4) $(\mathrm{n}=131) \quad(\mathrm{n}=50) \quad(\mathrm{n}=20)$

Allele H2 (600 bp) 0.67

$0.26 \quad 0.25$

$0.74 \quad 0.75$

Chromosomal Location: The LPL-gene is located on chromosome 8p22 (6).

Reaction Conditions and Analysis: We used genomic DNA in the PCR-reaction. The primer-concentration is $160 \mathrm{ng} / \mathrm{ml}$, the $\mathrm{Mg}^{++}$-concentration is $2 \mathrm{mM}$ and the dNTP-concentration is $200 \mu \mathrm{M}$. The temperature profile is a) denaturation for $1 \mathrm{~min}$ at $95^{\circ} \mathrm{C}$, b) annealing for $1 \mathrm{~min}$ at $50^{\circ} \mathrm{C}$ and c) extension for $1 \mathrm{~min}$ at $72^{\circ} \mathrm{C}$. We used 30 cycles. The reaction products were analysed on $2 \%$ agarose in TBE after HindIII-digestion.

References: 1) Wion,K.L. et al. (1987) Science 235, 1638-1641. 2) Kirchgessner,T.G. et al. (1989) Proc. Natl. Acad. Sci. USA 86, 9647-9651. 3) Oka,K. et al. (1990) Biochem. Biophys. Acta 1049, 21-26. 4) Funke,H. et al. (1987) Nucl. Acids Res. 15, 9102. 5) Heinzmann, C. et al. (1987) Nucl. Acids Res. 15, 6763. 6) Sparkes,R.S. et al. (1987) Genomics 1, 138-144.

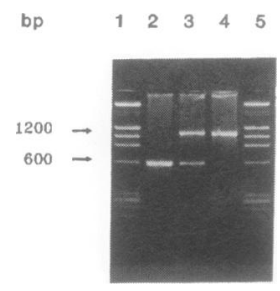

Figure 1. Individuals who are homozygous for presence (lane 2) or absence (lane 4 ), or who are heterozygous for the HindIII- restriction site (lane 3). The DNAmolecular weight marker (lane $1+5$ ) is a combination of $\lambda$-DNA cut with HindIII and $\phi \mathrm{X}-174-\mathrm{RF}$ DNA cut with HaeIII. 